\title{
Acute effect of self-myofascial release using a foam roller on the plantar fascia on hamstring and lumbar spine superficial back line flexibility
}

\author{
Kwangsun Do ${ }^{a}$, Jaeeun $\mathrm{Kim}^{\mathrm{b}}$, Jongeun $\mathrm{Yim}^{\mathrm{c}}$ \\ aDepartment of Physical Therapy, International St. Mary's Hospital, Catholic Kwandong University, Incheon, Republic of Korea \\ ${ }^{b}$ Department of Physical Therapy, Barosun Hospital, Seoul, Republic of Korea \\ 'Department of Physical Therapy, College of Health Science and Social Welfare, Sahmyook University, Seoul, Republic of Korea
}

Objective: The purpose of this study was to investigate the immediate effect of applying self-myofascial release (SMR) to the plantar fascia using a foam roller on hamstring and lumbar spine superficial back line (SBL).

Design: Randomized controlled trial.

Methods: Thirty-one healthy adults agreed to the method and purpose of the study. Selection and exclusion criteria were screened, and baseline measurements for the Toe Touch test and passive straight leg raise (PSLR) test were obtained. The participants were then randomly assigned to the SMR group or the sham group. After group assignment, the SMR group rolled the surface of the foot from the heel to the metatarsal head using a foam roller for 5 minutes. The sham group received passive mobilization of the ankle joint in the supine position. Afterwards, the Toe Touch test and the passive straight leg-raise test were re-assessed.

Results: In the SMR group, the Toe Touch test results showed significant improvement $(p<0.05)$. Left and right PSLR test results showed a significant increase $(p<0.05)$. In the sham group, there was no significant difference between pre and post-test results. The SMR group showed a significant difference in the PSLR test and Toe Touch test compared to the sham group $(p<0.05)$.

Conclusions: The results of this study showed that SMR on the plantar fascia was immediately effective for improving the flexibility of the SBL of the lumbar spine and hamstring.

Key Words: Plantar fascia, Range of motion, Self-myofascial release, Superficial back line

\section{Introduction}

Flexibility can be defined as the ability for muscle stretch to enable movement of a joint as far as the range of motion, which is an essential component of normal biomechanical function [1]. A change in flexibility is necessary for all movements because it can cause abnormal loads and result in damage to the musculoskeletal system [2,3]. One of the factors that cause damage to the lines of the musculoskeletal system is insufficient flexibility [4,5].
The thin sheets of fascia and connective tissue fibers that form a line can form a pathway, which is called the myofascial meridians. Among them, the superficial back line (SBL) is a plantar aponeurosis, achilles tendon and gastrocnemius, popliteus, hamstring, sacrotuberous ligament, sacrolumbar fascia, erector spinae, and galea aponeurotica/epicranial fascia. The SBL functions as a single continuous line with integrated muscle fascia. For example, plantar fasciitis is associated with tachypnea tension, lumbar lordosis, and resistance to superficial cervical spondylosis [6,7]. Because

Received: 17 January, 2018 Revised: 12 March, 2018 Accepted: 13 March, 2018

Corresponding author: Jongeun Yim (ORCID http://orcid.org/0000-0001-7510-8233)

Department of Physical Therapy, College of Health Science and Social Welfare, Sahmyook University, 815 Hwarang-ro, Nowon-gu, Seoul 01795, Republic of Korea

Tel: 82-2-3399-1635 Fax: 82-2-3399-1639 E-mail: jeyim@syu.ac.kr

(c) This is an Open-Access article distributed under the terms of the Creative Commons Attribution Non-Commercial License (http://creativecommons.org/licenses/ by-nc/4.0) which permits unrestricted non-commercial use, distribution, and reproduction in any medium, provided the original work is properly cited.

Copyright $\odot 2018$ Korean Academy of Physical Therapy Rehabilitation Science 
the hamstring and calf muscles are a connected continuity, the reduced flexibility and stiffness of the hamstring may be the cause of plantar fasciitis [8].

There are several methods for increasing the flexibility of the fascia including the Rolfing, instrument-assisted fascial release, connective tissue massage, myofascial trigger point therapy, muscle energy techniques, and strain-counter strain [9]. One of the most common manipulative techniques, the myofascial release (MFR), helps to reduce fibrous adhesion or limited membrane between fascial tissue layers [10]. The self-myofascial release (SMR) has the same theory as the MFR, which can be applied by self under the supervision of a therapist [11]. It has been developed from the myofascial release as a principle that stimulates the muscles, tendons, and mechanoreceptors of the fascia and biomechanically loads the soft tissues [12]. The Golgi tendon organ (GTO) reflex arc model and other mechanoreceptors are the two mechanisms for increasing fascia mobilization using SMR. When the muscles are stretched, GTOs provide afferent feedback to the spinal cord. As pressure increases in the fascia by MFR or SMR, it stimulates GTOs, which reduces the motor unit firing rate and consequently reduces muscle tone

Table 1. General characteristics

$(\mathrm{N}=31)$

\begin{tabular}{lcc}
\hline \multicolumn{1}{c}{ Characteristic } & SMR group $(\mathrm{n}=15)$ & Sham group $(\mathrm{n}=16)$ \\
\hline Sex $($ male/female) & $10 / 5$ & $9 / 7$ \\
Height $(\mathrm{cm})$ & $170(7.68)$ & $168.4(7.44)$ \\
Weight $(\mathrm{kg})$ & $65.73(10.55)$ & $60.18(11.88)$ \\
Age $(\mathrm{y})$ & $30.53(3.6)$ & $23.93(4.9)$ \\
\hline
\end{tabular}

Values are presented as number only or mean (SD). SMR: self-myofascial release.

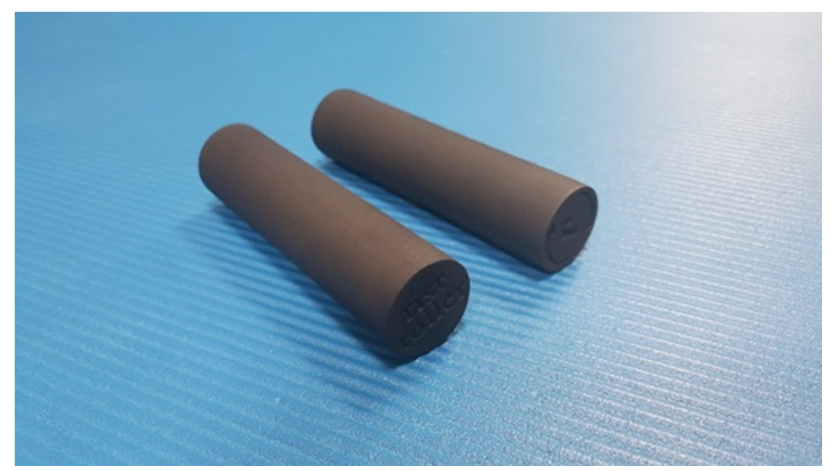

Figure 1. Micro foam roller (Ristroller, USA). The micro foam roller is device designed for release the forearm and plantar fascia with rolling motion. Small design of Foam rollers, commonly known as fascia relaxation.
[13]. The Ruffini and Pacinian corpuscles and the interstitial muscle receptors are the mechanoreceptors that are also involved in the neurophysiological mechanism for increasing fascia mobilization using SMR [14]. As pressure increases, the mechanical receptors stimulate the nervous system, thereby reducing muscle tone [15].

In previous studies, many studies have been conducted to improve flexibility using SMR [10,11,16-20]. Studies have focused mainly on the muscles that are to be increased. According to Anatomy Trains [7], there is a way to observe the association of the SBL. Myers [7] advocates that the effect of SBL can be seen through a simple test of rolling a tennis ball or golf ball on the plantar fascia. Relaxing the plantar fascia has additional effects on the hamstring and lumbar spine, which have the same myofascial train. This means that when one part of the body is relaxed, it affects the other connected fascia. However, this proposal has had some clinical effects, and no evidence has been provided through formal studies.

Therefore, the purpose of this study was to investigate the immediate effect of applying SMR to the plantar fascia using foam roller on hamstring and lumbar spine.

\section{Methods}

\section{Subjects}

Thirty-one healthy adults agreed to the method and purpose of the study. The selection criterion was defined as having no problems in the back and lower back, pain, sensory

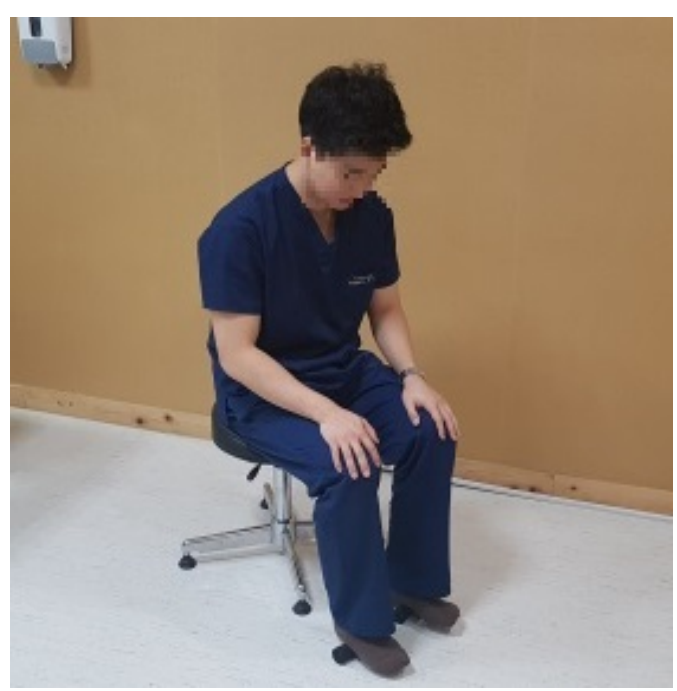

Figure 2. Position of the foam roller on the plantar fascia during self-myofascial release. 
abnormality, and other lower extremity and lumbar problems within the past 6 months. In addition, the Toe Touch test excluded those who could reach the floor. The characteristics of the study subjects are shown in Table 1.

This study was approved by the Institutional Review Board of the Sahmyook University (IRB No. 2-1040781AB-N-01-2018009HR).

\section{Procedure}

The selection and exclusion criteria were screened, and Toe Touch test and passive straight leg raise (PSLR) test baseline were measured. The participants were then randomly assigned to the experimental group (SMR) or control group (Sham) and randomly used the online tool "Graph Pad" (GraphPad Software, San Diego, CA, USA; http:// www.graphpad.com/quickcalcs/randomize1.cfm/). After group assignment, the SMR group rolled the surface of the foot from the heel to the metatarsal head for 5 minutes using a foam roller (Figures 1, 2) [21]. Participants were instructed to apply as much pressure as possible without pain [22]. Then, the Toe Touch test and the PSLR were re-measured. The sham group received passive mobilization of the ankle joint while being in a supine position. Passive movements applied in a randomized order were supination, pronation, abduction, adduction, flexion, and extension. Subjects were given 5 minutes of mobilization [23].

\section{Outcome measures}

\section{Toe Touch test}

Subjects were asked to stand up straight on a $20-\mathrm{cm}$ high

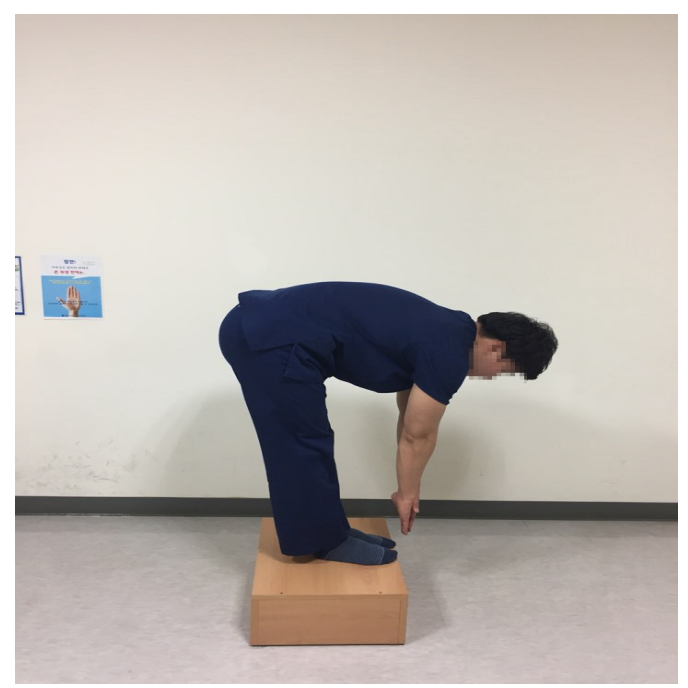

Figure 3. Toe Touch test. platform with feet together and no shoes. Then, the subjects were instructed to bend down towards the platform as much as possible while keeping the knees, arms, and fingers in full extension. (Figure 3). The distance from the tip of the middle finger and the platform was measured in centimeters with a supple measuring tape. If the tip of the middle finger could not reach the platform, the test was considered positive. If the subject could reach past the platform, the test was considered negative. Both evaluators were experienced in measuring the finger-to-floor distance. The intra-class correlation coefficient (ICC) of the Toe Touch test was 0.99 . The Spearman's correlation coefficient for trunk flexion assessed by the test and the radiologic measure was -0.96 [24].

\section{Passive straight leg raise}

PSLR was conducted with the subject in supine position on a medical bed. The examiner performed the PSLR by keeping the knee in full extension and the ankle in neutral position. Full ankle dorsiflexion was avoided to prevent calf muscle stiffness or pain (gastrocnemius and soleus) from confounding the sensation of hamstring stiffness and pain, which would signal the limit of the PSLR test. The examiner stabilized the talus in order to prevent any hip rotation during hip flexion. The examiner lifted the subject's lower limb until the subject began to complain of pain or stiffness in the thigh region, perform knee flexion, or swing into a posterior pelvic tilt position (noted as movement of the anterior superior iliac spine). Range of motion measurements for the PSLR were taken using Clinometer (Plaincode, Stephan-

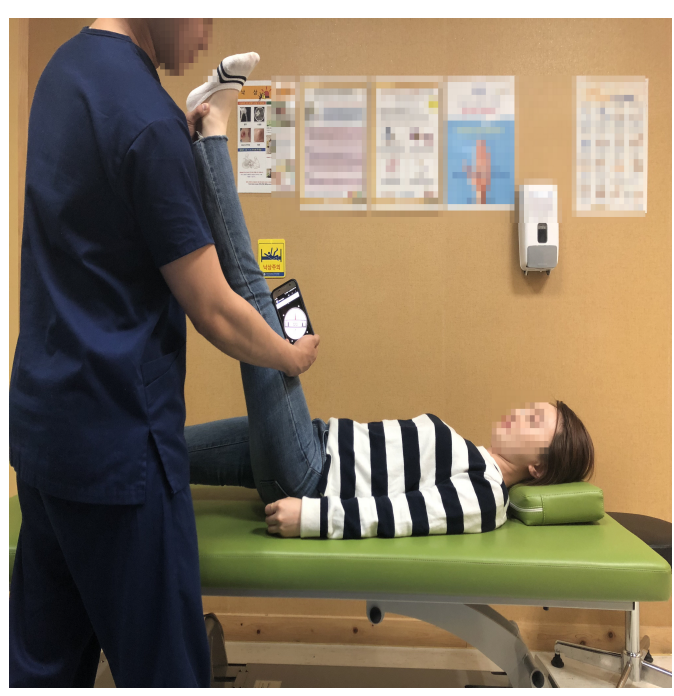

Figure 4. Passive straight leg raise. 
skirchen, Germany; http://www.plaincode.com/products/clinometer/), which is a smart phone application that has previously been shown to be reliable at measuring range of motion of the shoulder. The intra-observer reliability of the smartphone inclinometric and goniometric measurements was ICC value $>0.9$ [25]. The upper part of the patella was marked and the end of the smart phone was aligned (Figure 4).

\section{Statistical analysis}

Results were analyzed using the SPSS ver. 15.0 (SPSS Inc., Chicago, IL, USA). For the general subject characteristics, the descriptive statistics was conducted. To examine the changes in PSLR and Toe Touch results before and after intervention, the paired t-test was performed. To compare the PSLR and Toe Touch test results between the SMR and the Sham group, the independent t-test was performed. The statistical significance was assumed to be $\alpha=0.05$.

\section{Results}

This study selected 31 healthy adults who passed the selection criteria. The general characteristics are shown (Table 1).

Before the experiment, there were no significant differences in PSLR and Toe Touch test results between the SMR group and the Sham group (Table 2). In the SMR group, the

Table 2. Comparison of PSLR and Toe Touch test between two groups

$(\mathrm{N}=31)$

\begin{tabular}{lccc}
\hline \multicolumn{1}{c}{ Variable } & $\begin{array}{c}\text { SMR group } \\
(\mathrm{n}=15)\end{array}$ & $\begin{array}{c}\text { Sham group } \\
(\mathrm{n}=16)\end{array}$ & $\mathrm{t}(p)$ \\
\hline Left PSLR & & & \\
Pre-test & $45.6(7.10)$ & $51.43(10.25)$ & $-1.83(0.07)$ \\
Post-test & $54.13(8.12)$ & $52.06(10.20)$ & $0.62(0.53)$ \\
$\mathrm{t}(p)$ & $-6.95(<0.001)$ & $-0.59(0.56)$ & \\
Change value & $8.53(4.74)$ & $0.62(4.20)$ & $4.91(<0.001)$ \\
Right PSLR & & & \\
Pre-test & $45.27(5.99)$ & $49.93(7.46)$ & $-1.91(0.06)$ \\
Post-test & $53.73(8.87)$ & $48.43(8.64)$ & $1.68(0.10)$ \\
$\mathrm{t}(p)$ & $-5.66(<0.001)$ & $1.66(0.11)$ & \\
Change value & $8.46(5.79)$ & $-1.50(3.61)$ & $5.78(<0.001)$ \\
Toe Touch test & & & \\
Pre-test & $17.88(6.98)$ & $17.76(9.59)$ & $0.39(0.96)$ \\
Post-test & $13.22(6.91)$ & $16.28(8.37)$ & $-1.10(0.27)$ \\
$\mathrm{t}(p)$ & $6.76(<0.001)$ & $2.11(0.05)$ & \\
Change value & $-4.66(2.66)$ & $-1.47(2.78)$ & $-3.24(<0.001)$ \\
\hline
\end{tabular}

Values are presented as mean (SD).

PSLR: passive straight leg raise, SMR: self-myofascial release.
Toe Touch test results showed a significant improved, from 17.88 to $13.22(p<0.05)$. Left PSLR significa ntly increased from 45.6 to $54.13(p<0.05)$. Right PSLR significantly increased from 45.27 to $53.73(p<0.05)$. In the Sham group, there were no significant differences between pre and post test. The SMR group showed a significant difference in PSLR and Toe Touch test results compared to the Sham group $(p<0.05$; Table 2$)$.

\section{Discussion}

There is a hypothesis that an increase in muscle tension in one part of the body causes excessive tension in other parts of the body due to the continuity of the body. This continuity of the fascia can cause stress on not only the muscles but all the structures that are surrounded and supported by the fascia [7]. Based on this hypothesis and anatomy, Myers [7] supported the increase in the Toe Touch test when the plantar fascia at the end of the SBL was released. However, some clinical effects were claimed and there were no formal studies. Therefore, the purpose of this study was to investigate the effect of performing SMR to the plantar fascia on hamstring and lumbar spine flexibility.

The PSLR and Toe Touch results of the SMR group were significantly increased after intervention $(p<0.05)$ and also showed a significant difference compared to the Sham group. There was no significant difference in the Sham group pre and post intervention. These results suggest that the SMR of the plantar fascia was immediately effective for the lumbar and hamstring flexibility. There have been many studies on the effect of SMR on the range of motion and flexibility $[10,11,20,26]$. However, previous research on increasing flexibility has been limited to selected parts of the body. There has been no research showing the effects of applying SMR to one part of the body may affect other parts of the body. According to the Anatomy Trains [7], SMR applied to the plantar fascia is effective in increasing flexibility anywhere along the SBL, but no evidence has been suggested through formal studies. However, this study found that the application of SMR using a foam roller to the plantar fascia could support the concept of increased flexibility of other body parts connected by myofascial meridians such as hamstring and lumbar spine.

Although we did not use SMR, there are some studies that have experimented with the concept of myofascial meridians. An RCT investigated the effects of hamstring passive stretching on the range of motion of the neck in healthy 
adults. The range of motion of the cervical, which is the ascending part of SBL, increased after hamstring stretching [27]. According to Spina [28], a patient with chronic hamstring pain was relieved of pain and dysfunction by applying an active release technique to the SBL, the lumbar spine, and calf. Akhbari et al. [29] reported that a patient with chronic plantar fasciitis was treated with dry needling on the Achilles tendon, medial gastrocnemius, biceps femoris, semimembranosus, and ischial tuberosity. After 4 treatments over 2 weeks, the patient showed a $60 \%$ to $70 \%$ reduction in pain.

Many anatomical books have described the function of muscles as separate from adjacent structures, excluding the upper and lower connective muscles, nerves and blood vessels. For example, it is simply defined that the distance between the origin and the insertion point of a particular muscle is close to the function of the muscle. Separate thinking of the muscles makes it difficult for current-generation therapists to have different views on the function of muscles and muscles [7]. This is similar to the view that clinicians limit the treatment to the area of pain or discomfort. In the future, it will be possible to get more effective treatments if you use a mixture of extended concepts such as myofascial meridian.

The limitation of this study is the lack of the number of experimental groups. Secondly, there is a lack of clinically relevant thinking about the application to healthy adults. In the future, it is hoped that further studies will be conducted to investigate the effects of the disease on pain and function.

The results of this study showed that SMR on the plantar fascia was immediately effective for improving the flexibility of the SBL of the lumbar spine and hamstring. These results suggest that in order to increase flexibility, interventions should be made not only to the body part but also to other parts of the body, taking into account the continuity of the myofascial meridian.

\section{Conflict of Interest}

The authors declared no potential conflicts of interest with respect to the authorship and/or publication of this article.

\section{References}

1. Hopper D, Deacon S, Das S, Jain A, Riddell D, Hall T, et al. Dynamic soft tissue mobilisation increases hamstring flexibility in healthy male subjects. Br J Sports Med 2005;39:594-8; discussion 598.

2. Wilson A. Effective management of musculoskeletal injury: a clinical ergonomics approach to prevention, treatment and rehabilitation. Edinburgh: Elsevier Health Sciences; 2002.

3. Ylinen J. Stretching therapy for sport and manual therapies. Edinburgh: Elsevier Health Sciences; 2008.

4. Davis DS, Ashby PE, McCale KL, McQuain JA, Wine JM. The effectiveness of 3 stretching techniques on hamstring flexibility using consistent stretching parameters. J Strength Cond Res 2005;19:27-32.

5. Decoster LC, Scanlon RL, Horn KD, Cleland J. Standing and supine hamstring stretching are equally effective. J Athl Train 2004;39:330-4.

6. Schleip R, Findley TW, Chaitow L, Huijing P. Fascia: the tensional network of the human body-e-book: the science and clinical applications in manual and movement therapy. Churchill Livingstone: Elsevier; 2013. p. 131.

7. Myers TW. Anatomy trains: myofascial meridians for manual and movement therapists [E-book]. Churchill Livingstone: Elsevier Health Sciences; 2013.

8. Bolívar YA, Munuera PV, Padillo JP. Relationship between tightness of the posterior muscles of the lower limb and plantar fasciitis. Foot Ankle Int 2013;34:42-8

9. Simmonds N, Miller P, Gemmell H. A theoretical framework for the role of fascia in manual therapy. J Bodyw Mov Ther 2012;16: 83-93.

10. MacDonald GZ, Penney MD, Mullaley ME, Cuconato AL, Drake CD, Behm DG, et al. An acute bout of self-myofascial release increases range of motion without a subsequent decrease in muscle activation or force. J Strength Cond Res 2013;27:812-21.

11. Sullivan KM, Silvey DB, Button DC, Behm DG. Roller-massager application to the hamstrings increases sit-and-reach range of motion within five to ten seconds without performance impairments. Int J Sports Phys Ther 2013;8:228-36.

12. Remvig L, Ellis RM, Patijn J. Myofascial release: an evidencebased treatment approach? Int Musculoskelet Med 2008;30:2935 .

13. Tozzi P. Selected fascial aspects of osteopathic practice. J Bodyw Mov Ther 2012;16:503-19.

14. Stecco C, Gagey O, Belloni A, Pozzuoli A, Porzionato A, Macchi V, et al. Anatomy of the deep fascia of the upper limb. Second part: study of innervation. Morphologie 2007;91:38-43.

15. Schleip R. Fascial plasticity-a new neurobiological explanation: part 1. J Bodyw Mov Ther 2003;7:11-9.

16. Grieve R, Goodwin F, Alfaki M, Bourton AJ, Jeffries C, Scott H. The immediate effect of bilateral self myofascial release on the plantar surface of the feet on hamstring and lumbar spine flexibility: a pilot randomised controlled trial. J Bodyw Mov Ther 2015;19:544-52.

17. Halperin I, Aboodarda SJ, Button DC, Andersen LL, Behm DG. Roller massager improves range of motion of plantar flexor muscles without subsequent decreases in force parameters. Int $\mathbf{J}$ Sports Phys Ther 2014;9:92-102.

18. Mikesky AE, Bahamonde RE, Stanton K, Alvey T, Fitton T. Acute effects of The Stick on strength, power, and flexibility. J Strength Cond Res 2002;16:446-50.

19. Roylance DS, George JD, Hammer AM, Rencher N, Gellingham 
GW, Hager RL, et al. Evaluating acute changes in joint range-of-motion using self-myofascial release, postural alignment exercises, and static stretches. Int J Exerc Sci 2013;6:310-9.

20. Škarabot J, Beardsley C, Štirn I. Comparing the effects of self-myofascial release with static stretching on ankle rangeof-motion in adolescent athletes. Int J Sports Phys Ther 2015;10: 203-12.

21. Yadav AO, Lakshmiprabha R. Comparison of the effects of therapeutic ultrasound $\mathrm{v} / \mathrm{s}$ myofascial release technique in treatment of plantar fasciitis. Indian J Physiother Occup Ther Int J 2012;6: 13-6.

22. Curran PF, Fiore RD, Crisco JJ. A comparison of the pressure exerted on soft tissue by 2 myofascial rollers. J Sport Rehabil 2008; 17:432-42.

23. Castellote-Caballero Y, Valenza MC, Puentedura EJ, Fernándezde-Las-Peñas C, Alburquerque-Sendín F. Immediate effects of neurodynamic sliding versus muscle stretching on hamstring flexibility in subjects with short hamstring syndrome. J Sports Med (Hindawi Publ Corp) 2014;2014:127471.

24. Perret C, Poiraudeau S, Fermanian J, Colau MM, Benhamou
MA, Revel M. Validity, reliability, and responsiveness of the fingertip-to-floor test. Arch Phys Med Rehabil 2001;82:1566-70.

25. Shin SH, Ro du H, Lee OS, Oh JH, Kim SH. Within-day reliability of shoulder range of motion measurement with a smartphone. Man Ther 2012;17:298-304.

26. Fairall RR, Cabell L, Boergers RJ, Battaglia F. Acute effects of self-myofascial release and stretching in overhead athletes with GIRD. J Bodyw Mov Ther 2017;21:648-52.

27. Hyong IH, Kang JH. The immediate effects of passive hamstring stretching exercises on the cervical spine range of motion and balance. J Phys Ther Sci 2013;25:113-6.

28. Spina A. Treatment of proximal hamstring pain using active release technique applied to the myofascial meridian: a case report [Internet]. San Francisco (CA): SCRIBD, 2011 [cited 2018 Jan 17]. Available from: https://www.scribd.com/document/82089618/ Treatment-of-Proximal-Hamstring-Pain-Using-Active-Release-Te chnique.

29. Akhbari B, Salavati M, Ezzati K, Mohammadi Rad S. The use of dry needling and myofascial meridians in a case of plantar fasciitis. J Chiropr Med 2014;13:43-8. 